\title{
Principals' Perceptions of Education Equity: A Mindset for Practice
}

\author{
Louis S. Nadelson ${ }^{1}$, Shelly Albritton ${ }^{1}$, Valerie G. Couture ${ }^{1}$, Charlotte Green ${ }^{1}$, Stacey D. Loyless ${ }^{1} \&$ Erin O. Shaw ${ }^{1}$ \\ ${ }^{1}$ University of Central Arkansas, Conway, AR, USA \\ Correspondence: Louis S. Nadelson, Deparmternt of Leadership Studies, University of Central Arkansas, Conway, \\ AR., 72035, USA. E-mail: lnadelson1@uca.edu
}

Received: October 5, 2019 Accepted: November 3, 2019 Online Published: November 11, 2019

doi:10.5539/jel.v9n1p1 URL: https://doi.org/10.5539/jel.v9n1p1

\begin{abstract}
In an effort to define a principal education equity mindset, we initially identified six essential attributes of the construct and attempted empirically to confirm our definition by gathering a combination of quantitative and qualitative data from 128 principals. We found variations in the expression of the mindset attributes and commitment by principals to create conditions that support success for all students. In addition, we exposed two unanticipated attributes and variations on attribute commitment. The principals' personal, professional, and school variables were associated with significant differences in the mindset attributes. We provide a discussion of our findings, implications for practice, and directions for future research.
\end{abstract}

Keywords: mindset, leadership, education equity, principal, success for all

\section{Introduction}

Leadership has considerable influence on the climate, priorities, and personnel within a school (Gardiner \& Enomoto, 2006). School principals can inspire or suppress a climate of assuring equitable education for all students (Theoharis, 2008). Principals supporting equitable education create a climate and culture of equity through their instructional leadership, collaboration, advocacy, encouragement of transformation, and engagement in evidence-based practice (Theoharis \& Haddix, 2011). We maintain that if principals are going to be effective at supporting educational equity, they must hold an education equity mindset. We consider a principal education equity mindset to be the embrace of a philosophy that motivates engagement in actions that increase opportunities for all students to achieve to their highest capacity.

In our search of the literature, we were able to find multiple reports on measuring aspects of education equity (e.g., Hernandez \& Kose, 2012), but we were not able to locate any studies empirically documenting an education equity mindset of principals. Since there is a need for principals to have the mindset to effectively implement an education equity culture, there is justification for creating and empirically documenting a model for principals' education equity mindset. The gap in the literature and the warrant for our research lead us to wonder; what are the attributes of a school leader education equity mindset model, how are the attributes related, how does the mindset manifest in principals' work, and how are the attributes related to differences in personal and professional variables.

\section{Review of Literature}

\subsection{Educational Equity Mindset}

School leadership is a complex endeavor that can maintain status quo or lead to system transformation (Grigsby, Schumacher, Decman, \& Simieou, 2010). The mindset of a principal is likely to provide insight into their priorities, vision, and anticipated actions, and into the personal philosophy they use to guide their work (Rowley, 1991). Mindsets, particularly in association with a complex situation (e.g., education equity), are typically multifaceted constructs that can be conceived in multiple ways through different lenses (Armor \& Taylor, 2003; French, 2016; Gollwitzer \& Bayer, 1999). Through French's (2016) review of different mindset conceptions he argues that mindsets should be considered as being on a spectrum rather than constrained to a specific set of criteria. Embracing French's recommendation, we define mindset as a combination of perceptions, attitudes, beliefs, thoughts, dispositions, that can be used to explain personal actions and/or choices. Thus, a mindset is reflective of the identity of individuals - how they perceive themselves - which in turn influences how they interact with others, and how they perceive their environment and responsibilities (Taylor \& Gollwitzer, 1995).

Situating our conception of mindset within the perception of education equity, we created a model of an education 
equity mindset for school leaders. We contend that a school leader education equity mindset guides the promotion and support of equitable education. We have adopted Jordan's (2010) definition of education equity to encompass the broader student population and associated factors such as ethnicity, social economic status, gender, disabilities, community, and resources. Thus, we consider an education equity mindset to be a deeply held personal thought structure used by individuals to advocate for and work toward equitable education for all learners. We argue that school principals' expression of an education equity mindset manifests as: engagement in instructional leadership, influences organizational culture and climate, expression of transformative leadership, embraces collaborative leadership, advocacy for educational equity, and partakes in evidence-based decision making. Because a principal's beliefs, knowledge, and dispositions are critical to forming and sustaining an environment in which all students achieve to their highest capacity, we maintain there is merit in assessing the extent to which principals hold and express an education equity mindset.

\subsection{Instructional Leadership}

A pervasive gap in achievement continues to plague our nation (Hung et al., 2019), which is reflective of a lack of education equity. We argue that principals who hold an education equity mindset are more likely to take the position of instructional leader and address instructional conditions to reverse the perpetuation of education inequity. School leaders who hold an education equity mindset are also more likely to support instructional cultures or frameworks that foster teachers' beliefs that all students can grow, learn, and succeed (Dweck, 2007; Farrington et al., 2012).

We argue that through instructional leadership, principals can catalyze teacher focus on affording students with opportunities to make connections, think analytically, solve problems, and perhaps even make contributions of new understandings within the body of knowledge (Barth, 2001). Currently, marginalized and underserved populations are often provided with fewer rigorous, challenging, and relevant instructional experiences than the more mainstream peers (Oakes, 2005). Similarly, Hammond (2015) argues that by not taking advantage of opportunities to develop critical thinking and creative problem-solving habits, schools are supporting conditions of educational inequity. As a result, many marginalized and underserved students are likely to leave our educational systems as dependent learners instead of independent thinkers, severely limiting their potential (Hammond, 2015). We embrace the notion that principals are fundamental to guiding instructional decisions that elevate educators' goals beyond focusing on test-prep activities for their students which typically involve low levels of engagement (Conley, 2011; Kohn, 2008; Yair, 2000).

Evidence suggests that if multiple perspectives are considered and equity-based leadership approaches are emphasized, school leaders can transform and improve instructional experiences and achievement for larger numbers of culturally and linguistically diverse learners in the K-12 educational process (Ehren, 2009; Santamaria \& Santamaria, 2012; Tooms \& Boske, 2010). Principals with an education equity mindset are more likely to promote teacher engagement in quality instructional experiences that are rigorous, aligned with content standards, and use various differentiated instructional strategies to meet the academic needs of all students - an approach that is fundamental to a culture of learning equity (Normore, 2008; Scigliano \& Hipsky, 2010; Shapiro, 2008; Weiss \& Pasley, 2004).

The potential for principal instructional leadership to transform the education equity instructional approaches of teachers provides justification for considering instructional leadership as part of a principal education equity mindset. Thus, we argue that there is warrant to including the attribute of instructional leadership in our mindset model and assessing principals' levels of engagement and consideration of the attribute.

\subsection{Organizational Culture and Climate Leadership}

Over a century ago the pioneer of educational administration research, Ellwood Cubberley observed, "As is the principal, so is the school" (1916, p. 15); which reflects an early recognition for the importance of leadership quality and its effect on school climate and culture. According to Robinson (2010), student learning is directly influenced by the actions of the principal. School success depends on effective leadership to develop the conditions for a school's climate and culture to flourish and meet the academic, physical, social, and emotional needs of all its students (Hoy, Tarter, \& Kottkamp, 1991; Hoyle, English, \& Steffy, 1985; Louis, Leithwood, Wahlstrom, \& Anderson, 2010; Turan \& Bektas, 2013). Because of the influence that principals have on school climate and culture and the conditions that lead to meeting the needs of all students, we have included the associational leadership focus or attribute in our model of an educational equity mindset.

School climate and school culture may be perceived as the same; however, there is a distinct difference between the two. Gruenert (2008) describes climate as being similar to attitude, and culture as being similar to personality. Gruenert also notes it is far easier to change an attitude than it is to change a personality, suggesting that it is easier 
to change a school climate than change a school culture. School climate can also be viewed as the way the school functions on a day-to-day basis and described using terms such as bright, warm, and sunny; or dark, cold, and stormy. In contrast, culture denotes a deeper dive into understanding the nuances of the shared values, norms, processes, language beliefs, and assumptions of those in the organization (Deal \& Peterson, 2009; Turan \& Bektas, 2013).

A number of leadership actions can influence school climates, including: 1) developing a shared vision; 2) establishing goals; 3) setting high expectations for educators, students, and parents; 4) building capacity; 5) distributing leadership; 6) focusing on teaching and learning; 7) supporting collaboration; 8) fostering organizational trust; 9) redirecting or changing the course of the organization; and 10) caring for the well-being of all students (Deal \& Peterson, 2009; Hoy et al., 1991; Hoyle et al., 1985; Louis et al., 2010; Robinson, 2010; Turan \& Bektas, 2013).

The school leaders who exercise their ability and power to transform or maintain a positive and inclusive climate and culture have the potential to increase the education equity of the organization. Because of the association between success for all and organizational culture and climate, there is justification for including the consideration and actions of principals associated with school culture and climate as part of an educational equity mindset.

\subsection{Transformational Leadership}

There is considerable overlap between educational equity and social justice (Jordan, 2010). Thus, to create and maintain a culture and environment of education equity requires embracing elements of social justice. When leaders promote social justice as part of their vision, they are likely to hold a transformational leadership philosophy (Brown, 2004). We maintain that part of a school leader educational equity mindset includes engaging in transformational leadership practices.

When principals engage in transformational leadership practices they promote equal treatment of all members of the school and community, promote the regard for people as individuals, provide everyone with an optimal opportunity to learn and grow to their full capacity, and when inequities remain, they are in favor of those who are of highest need and have the lowest advantage (Riester, Pursch, \& Skrla, 2002). Riester and colleagues (2002) report that principals who are transformational leaders assume a tremendous amount of responsibility for catalyzing change and are persistent to supporting the change when faced with barriers or challenges. Thus, principals as transformational leaders are advocates for change and promote new ways of thinking about underachievement, shifting the conversation from deficit model thinking to opportunity model thinking (Riester et al., 2002). Engaging in transformational leadership activities such as shifting the conversation from what is wrong with our students to discussions about what can we do to support our students' success, is reflective of an educational equity mindset.

Given the relationship between transformational leadership and educational equity, there is justification for examining the level to which principals embrace the elements of transformational leadership as part of their practice.

\subsection{Collaborative Leadership}

Collaborative leadership focuses on strategic, school wide actions shared by all stakeholders (administrators, teachers, parents and students) to concentrate on the continual improvement of student learning (Hallinger \& Heck, 2010a). Basic assumptions of collaborative leadership rely on policies and beliefs that foster shared commitments to achieving higher learning goals of students through broad participation and collaboration by all stakeholders in decision-making, and shared accountability for student learning outcomes (Hallinger \& Heck, 2010b). The potential for collaborative leadership to enhance the success for all and create the conditions of equity in education provide justification for considering the attribute as part of a principal education equity mindset.

Leaders who build a shared vision, foster the acceptance of group goals and maintain high-performance expectations, create the conditions for establishing a collaborative community of teachers, students, and community members (DeWitt, 2016; Leithwood, Harris, \& Hopkins, 2008). Providing individuals with the opportunity of shared leadership contributes to a positive school culture which can result in increases in student achievement (Leithwood et al., 2008). When principals enact core collaborative leadership practices, they can influence the motivation and beliefs which lead to significant influence on classroom practices and student learning (Leithwood et al., 2008).

The consideration and engagement in collaborative leadership has the potential to positively influence success for all students. As a result, we maintain that there is justification for including collaborative leadership as a fundamental attribute of a principal education equity mindset. 


\subsection{Advocacy for Educational Equity}

According to Theoharis (2005), advocacy for education equity is an aspect of social justice leadership. Education leaders who advocate for education equity address the inequity of student learning due to issues of race, class, gender, disability, sexual orientation, and other historically and currently marginalizing conditions as a fundamental part of their leadership practices and vision (Theorharis, 2005). School leaders who understand the importance of advocacy for education equity intentionally analyze student data with the lens of addressing and eliminating marginalization within their school. Thus, leaders who have internalized education equity advocacy have made the associated consideration and actions part of their mindset.

Leaders who promote advocacy for education equity are likely to embrace and support transformative learning and work toward changing perceptions of fixed abilities and expectations to a mindset of inclusiveness, reflection, and achievement. According to Mezirow (2003), transformative learning frames are effective because the frame is more likely to generate beliefs and opinions that will guide one to action. The principal who advocates for education equity is likely to hold a mindset in which they develop the culture of their school to have both direct and indirect influences on student achievement (Robinson, 2010).

Accepting the role of advocacy as part of the educational leadership mindset can transform school culture in a manner that promotes high achievement for all students, creates a sense of belonging for students and their families, and fosters an insightful culture that challenges teachers to become reflective about their values and beliefs. Thus, there is justification for considering advocacy as an attribute of an education equity mindset.

\subsection{Evidence-Based Decision Making}

Evidence-based decision making is a term which is used when school administrators use research on practices in schools and empirical data from relevant sources to make decisions (Finnigan, Daly, \& Che, 2012). Since many of the decisions that principals make can influence equitable education, evidence-based decision making is likely to be a critical attribute to an education equity mindset. By making decisions that are not evidence based there is a potential for embracing activities or processes that are ineffective, furthering the gaps in learning and increasing the inequity in education (Stanovich \& Stanovich, 2003).

Concerns within the United States about student's educational progress have been a part of the ongoing national dialog since the Nation at Risk Report (U.S. Department of Education, 1983), the No Child Left Behind Act of 2001 (Reddy, Kurz, \& Kettler, 2015), and the Every Student Succeeds Act (U.S. Department of Education, 2015). There is an increased responsibility on school administrators to provide data which supports their decision-making on conditions that enhance student success (Haecker, Lane, \& Zientek, 2017). School improvement from year-to-year is an expectation of a variety of stakeholders within an educational community, including; parents, students, teachers, administrators, and community leaders (Reddy et al., 2015). Thus, we argue that through the engagement in evidence-based decision making, principals are more likely to enhance the conditions in the school that lead to success for all and increases the equity of education in the organization.

School administrators have access to a multitude of student achievement and demographics data that can be used for decision making. However, even though school administrators have access to data, they may lack the mindset needed to use the data to positively affect student and school improvement (Means, Padilla, DeBarger, \& Bakia, 2009). It is possible for school administrators to become overwhelmed with multiple responsibilities reducing their interest or ability to consider using data to inform the development of opportunities designed to lead to the success of all the students in their schools (Haecker et al., 2017).

The influence that principal engagement in evidence-based decision making can have on assuring achievement for all students provides warrant for including the attribute in our model of principal education equity mindset. We maintain that it is critical for principals to hold a mindset that includes examining and applying data to assure the appropriate processes and conditions are in place to provide an environment conducive to educational equity for all students.

\section{Method}

The goal of our exploratory study was to begin to create an empirical foundation for effectively documenting the education equity mindset of school leaders. Our overarching research question: What attributes of an educational equity mindset are readily conveyed by K-12 school principals? To enhance our capacity to achieve our research goal we developed the following guiding research questions:

- When asked general questions about their role and practice what education equity mindset attributes do principals share? 
- How are principals' education equity mindset attributes related?

- What is the relationship among principals' focus on the attributes of education equity and variations in their personal, professional, and school variables?

- Are the activities that principals spend the majority of their time on during a typical work week aligned with an education equity mindset?

\subsection{Participants}

The 128 principals who fully completed our survey were recruited from a southern region of the United States. The participants had an average age of 48.77 years $(\mathrm{SD}=8.93)$, and had an average of 23.55 years $(\mathrm{SD}=8.76)$ experience in K-12 education. The participants were school leaders for an average of 10.98 years $(\mathrm{SD}=7.39)$, and had served in their current school for an average of 9.26 years $(\mathrm{SD}=9.11)$. The participants were evenly split between males and females. The majority (91\%) were Caucasian, $8 \%$ were African American, and 1\% were Hispanic. The principals' worked primarily in schools with students from low income (41\%) or low-middle income (45\%) families, with $14 \%$ working in schools with students from middle or upper-middle income families. The participants were primarily split between elementary schools (45\%), middle/junior high schools (21\%), and high schools $(25 \%)$, with the remaining $9 \%$ distributed in schools with other school configurations such as K-8, K-12, or 6-12 level students. The majority of the principals (78\%) indicated that less than $10 \%$ of their teachers were first year teachers, $17 \%$ indicated $10-20 \%$ of their teachers were first year teachers, and $5 \%$ indicated more than $20 \%$ of their teachers were first year teachers. The government evaluation of school performance level in which the participants worked were dispersed with $13 \%$ working in A schools, $42 \%$ in B schools, $33 \%$ in C schools, and $10 \%$ in D or F schools. The majority worked in rural communities $(59 \%)$ with a near even split between urban $(21 \%)$ and suburban $(20 \%)$ schools.

\subsection{Instrument Development}

Given the exploratory nature of our research, we realized we had to develop an instrument that focused on K-12 school principals' education equity mindset based on their perceptions and practices. While there is some foundational work associated with principals working toward education equity, we were not able to locate any studies specifically focused on exploring principals' education equity mindset. The lack of research tools led us to develop a survey to assess the extent to which K-12 principals embrace or consider aspects of an educational equity mindset.

We began our instrument development by brainstorming potential attributes of a school principal education equity mindset. Through discussion and consideration of the literature, we refined our list to those attributes that were directly aligned with an education equity mindset. Once we reached agreement on the essential attributes of an education equity mindset, we surveyed twelve school leader educators to establish validity for our list of constructs. Of the twelve educators, eight responded with agree or strongly agree to our recommended attributes.

Once we had validation of our education equity mindset attributes, we began to develop survey items aligned with the attributes, contextualizing the items for school leaders. We generated an extensive set of quantitative and qualitative items representative of consideration and application of principal education equity mindset. Acknowledging the limitations of time and attention that many principals can give to completing a survey we determined it was wise to focus on the selected response items that could be answered relatively quickly, but were also reflective of the mindset. We took a similar approach with our free response items, knowing we would limit the number and complexity of these in our final survey. Following our initial item development and review, we again went through the process of aligning our retained items with our attributes to assure we had a reasonable number of items to address each of our research questions, assess the principals' education equity mindset, and empirically test our model. Through the alignment process, we eliminated some items, added a few more and modified some resulting in at least two items for each mindset attribute.

Our final survey contained several demographic items, two free response items, and 17 selected response items. Our free response item included the prompts, "What is the most challenging part of your job?" and "What is one thing you do to ensure the well-being of all students?" Our selected response items included statements such as, "I advocate for changes to school policies to give the students a better chance to succeed" and "I expect my teachers to teach all students the same" which the participants responded to on a five-point Likert scale.

Following our development and refined selection of the survey items we distributed our draft survey to several school leader educators and asked them to provide us with feedback regarding the extent to which our items were representative of attributes of education equity. Based on the responses from the six educators who piloted our survey, we made minor adjustments to our items and determined that our prompts were valid for assessing 
principals' education equity mindset in alignment with our attributes.

\subsection{Data Collection}

Our data collection took place online. We used a publicly available list (from a state department of education) of principals and associated emails to invite principals to complete our online survey. We distributed an invitation email to the principals that contained a brief description of our research and a link to our survey. The first page of our survey contained our letter of information and an option to accept to share their data and participate in our research.

We collected data for one week and then distributed a reminder email of our invitation to participate in our research one week later. Our data collection took place over a three-week period.

\subsection{Analysis}

\subsubsection{Quantitative Data}

We began the analysis of our quantitative responses by conditioning our data which included removing responses that were not at least $90 \%$ complete. We then used the "replace missing values" feature in SPSS to insert the series mean for any skipped selected response items in the data set. Once our data set was complete, we again aligned our quantitative items to our attributes of an education equity mindset. We reverse coded the responses to our negatively phrase items and then calculated the composite scores for the groups of attributed items in preparation for our descriptive and inferential analysis.

\subsubsection{Qualitative Data}

To guide our analysis of the qualitative items we created a list of codes associated with the attributes we identified as being essential to an educational equity mindset of a school leader (see Table 1). In addition to the a priori codes, we also considered the possibility of emergent codes representative of the mindset attributes.

Table 1. Attributes of an education equity mindset and the associated codes

\begin{tabular}{ll}
\hline $\begin{array}{l}\text { Attribute of Educational } \\
\text { Equity Mindset }\end{array}$ & Codes \\
\hline Instructional Leadership (IL) & $\begin{array}{l}\text { Academic achievement, help other teachers be stronger, classroom observation, encourage teacher } \\
\text { creativity or innovation, professional development, learning, learner, conversations with teachers, quality of } \\
\text { instruction }\end{array}$ \\
$\begin{array}{l}\text { Organizational Culture and } \\
\text { Climate leadership (OCC) } \\
\text { expectations, inclusivity, trust, caring } \\
\text { Strong positive culture and climate lead to teacher satisfaction }\end{array}$ \\
$\begin{array}{l}\text { Transformative Leadership } \\
\text { (TL) }\end{array}$ & $\begin{array}{l}\text { Flexibility, choice, change, trust, autonomy in all individuals, progressive change, new goal, challenge, } \\
\text { make things different, move }\end{array}$ \\
Collaborative Leadership (CL) & $\begin{array}{l}\text { Working with struggling teachers, community, PLC's, shared vision, stakeholder input, voices of } \\
\text { stakeholders are heard, sharing best practices for the greater good }\end{array}$ \\
Advocacy for Educational & Focus on ALL student needs, helping families and children, have students best interest in mind, culturally \\
Equity (AEE) & $\begin{array}{l}\text { responsive, access to quality for all } \\
\text { Providing resources and services to help all students succeed }\end{array}$ \\
Evidence Based Decision & Analysis, data-driven, identify needs, uses data \\
Making (EBDM) & Make a difference, access to quality for all, rigor, student engagement, motivated learners \\
Student Success and &
\end{tabular}

\subsubsection{Coding}

We began our coding process as a group with all team members contributing to the discussion of coding the first 15 qualitative responses. Following the group experience two team members were assigned to independently code the same set of items. We formed three pairs of researchers and each pair coded a different subset of the data set. Once the independent coding was complete the pairs of coders met and discussed their results, and through discussion they came to consensus in their codings. 


\section{Results}

\subsection{Shared Attributes of an Education Equity Mindset}

Our first guiding research question was: When asked general questions about their role and practice, what education equity mindset attributes do principals share? To answer this question, we examined the results of coding our participants' responses to our questions asking the principals to share what is the primary role of a principal, and what they do to enhance student well-being. Again, our coding was focused on the attributes of an education equity mindset (see Table 1).

We found that the participants' responses to why they became a principal tended to focus on influence and reach, student success and achievement, and organizational climate (see Figure 1). To a lesser degree the participants also indicated instructional leadership and transformational leadership, forming and engaging in collaborative leadership teams. Few participants provided responses were reflective of advocating for education equity and none of the responses included references to evidence-based decision-making. Interpreted, the responses reflect a mindset of establishing a culture for student success with little consideration for advocating for education equity, collaborating on leadership, or using evidence to advance their agendas. See Table 2 for representative responses.

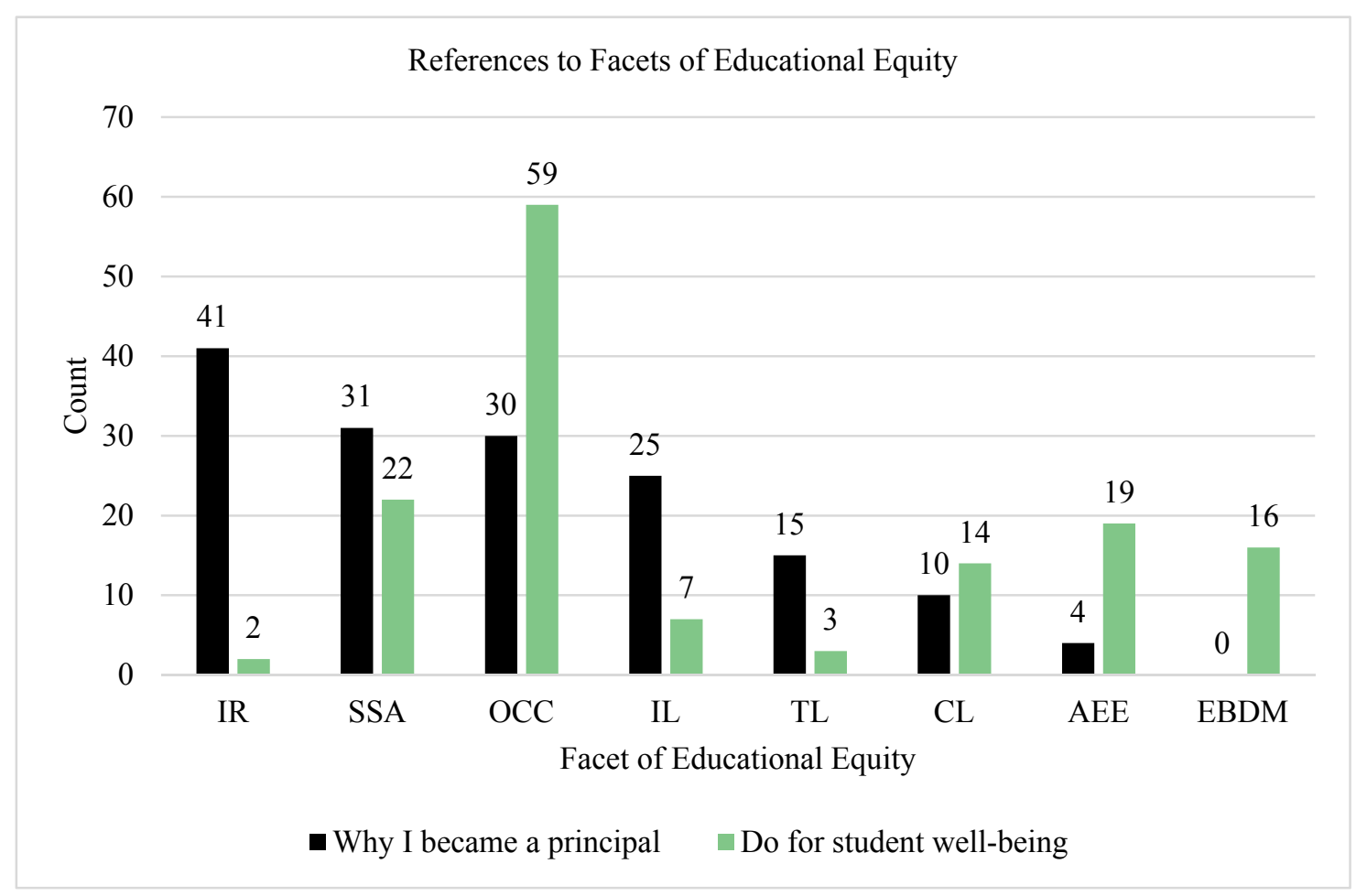

Figure 1 . The education equity mindset coded themes from our two qualitative items

Our analysis of the item asking the principals to share what they do to enhance student well-being indicated a shift in focus (see Figure 1). There was much more representation in the responses of organizational culture climate, advocating for educational equity, evidence-based decision making and collaborative leadership when compared to the responses to why the participants became school leaders. The responses to the student well-being item also reflected a reduction in emphasis on influence and reach, student success and achievement, instructional leadership, and transformational leadership when compared to the responses provided for becoming a principal (see Figure 1). See Table 2 for representative responses. 
Table 2. Participants responses aligned with attributes of education equity mindset

\begin{tabular}{|c|c|c|}
\hline $\begin{array}{l}\text { Attribute of Educational } \\
\text { Equity Mindset }\end{array}$ & Responses to why I became a principal & $\begin{array}{l}\text { Responses to what you do to enhance student } \\
\text { well-being }\end{array}$ \\
\hline Instructional Leadership (IL) & To apply my experience as a teacher. & Meet with PLC's groups once a month. \\
\hline $\begin{array}{l}\text { Organizational Culture and } \\
\text { Climate leadership (OCC) }\end{array}$ & $\begin{array}{l}\text { More flexibility to be in a position to make a } \\
\text { difference. }\end{array}$ & $\begin{array}{l}\text { I greet students at the front door each morning and } \\
\text { oversee them entering the building. I am also a } \\
\text { Commissioned School Security Officer. }\end{array}$ \\
\hline Transformative Leadership (TL) & $\begin{array}{l}\text { To be an instructional leader in the school to } \\
\text { lead teachers and students. }\end{array}$ & Addressing social, emotional and academic success. \\
\hline Collaborative Leadership (CL) & $\begin{array}{l}\text { I became a principal so that our faculty, staff, } \\
\text { and I could build a team that would work } \\
\text { together for the success of each individual } \\
\text { student. }\end{array}$ & $\begin{array}{l}\text { The RtI process addresses academics and } \\
\text { social/emotional behaviors. I sit down every Friday and } \\
\text { go student by student with my team to see where a kid is } \\
\text { and what we can do to move them along. }\end{array}$ \\
\hline $\begin{array}{l}\text { Advocacy for Educational } \\
\text { Equity (AEE) }\end{array}$ & $\begin{array}{l}\text { I became a principal so that our faculty, staff, } \\
\text { and I could build a team that would work } \\
\text { together for the success of each individual } \\
\text { student. }\end{array}$ & $\begin{array}{l}\text { Keep teachers focused on ALL the needs of our } \\
\text { students. }\end{array}$ \\
\hline $\begin{array}{l}\text { Evidence Based Decision } \\
\text { Making (EBDM) }\end{array}$ & N/A & $\begin{array}{l}\text { Monitor classroom teaching and data consistently and } \\
\text { frequently. }\end{array}$ \\
\hline $\begin{array}{l}\text { Student Success and } \\
\text { Achievement } \\
\text { (SSA) }\end{array}$ & $\begin{array}{l}\text { I wanted to help teachers and students } \\
\text { achieve more success. }\end{array}$ & $\begin{array}{l}\text { We use data and cross-reference these scores with other } \\
\text { data to ensure we are not letting certain students "fall } \\
\text { through the cracks." }\end{array}$ \\
\hline Influence and Reach (IR) & $\begin{array}{l}\text { To impact the lives of more students than I } \\
\text { could affect as a classroom teacher. }\end{array}$ & $\begin{array}{l}\text { I make myself available to students at all times. They } \\
\text { were told day } 1 \text { that I have an open-door policy and I } \\
\text { welcome them in my office to discuss a variety of issues } \\
\text { from the curriculum, to their overall safety. }\end{array}$ \\
\hline
\end{tabular}

\subsection{Relation Among Attributes}

Our second guiding research question asked: How are principals' education equity mindset attributes related? To answer this question, we examined the means and the correlations among the education equity mindset attribute composite scores (see Figure 2). Our analysis revealed agree to strongly agree levels for the student success and achievement attribute $(M=4.34, S D=.58)$ which we interpret as the principals on average are engaged at a high level in thinking about and acting upon activities aligned with student success. Both evidence-based decision-making $(M=3.94, S D=.56)$ and advocating for education equity $(M=3.87, S D=.63)$ were near the agree level, which we interpret as the principals on average are engaged at a moderate to high level in thinking about and engaging in activities that involve using data for decision-making and advocating for equity in education. Closer to the neutral level were the average responses to collaborative leadership $(M=3.58, S D=.49)$ and organization culture and climate $(M=3.47, S D=.52)$ which we interpret as moderate engagement in thinking about and acting on activities reflective of collaborations for decision-making and attempts to influence the school culture and climate. At the disagree level was instructional leadership $(M=2.01, S D=.83)$ which we interpret as the principals on average disagreeing that they needed to devote more time toward thinking about and engaging in activities reflective of leadership for instruction. Thus, our analysis revealed a substantial variation in the scores reflecting inconsistent consideration of or acting on the different attributes in our model. 


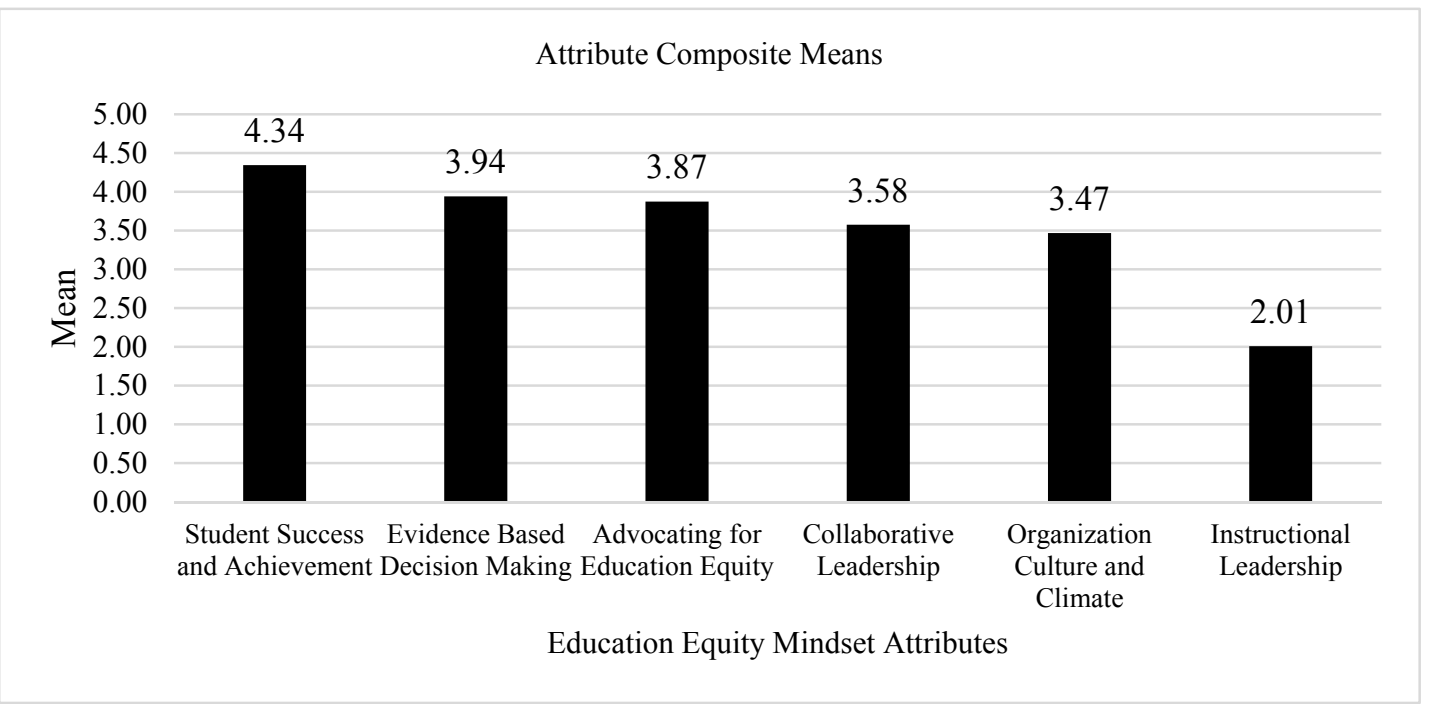

Figure 2. The average composite scores for our attributes of a principal education equity mindset

Our analysis also revealed few significant correlations among the composite scores (see Table 3). We found significant correlations between evidence-based decision making (EBDM) and advocating for educational equity (AEE) $p<.01$ and between evidence-based decision making (EBDM) and student success and achievement (SSA) $p<.01$. We also found student success and achievement (SSA) and advocating for educational equity (AEE) $p$ $<.05$. Interpreted, as principals increase their levels of evidence-based decision making, they are also likely to experience increases in their levels of advocating for educational equity, and for students' success and achievement. Similarly, our results indicate that as levels of student success and achievement increase the levels of advocating for educational equity also increases. Our results again reflect an inconsistent consideration or actions associated with the attributes of our education equity mindset model.

Table 3. Correlations among the attributes of an educational equity mindset

\begin{tabular}{llllll}
\hline & AEE Composite & IL Composite & OCC Composite & EBDM Composite & SSA Composite \\
\hline CL Composite & .12 & .07 & .10 & -.01 & .13 \\
AEE Composite & & -.15 & .15 & $.31^{* *}$ & $.21^{*}$ \\
IL Composite & & .14 & .05 & .13 \\
OCC Composite & & & .12 & .07 \\
EBDM Composite & & & & $.23^{* *}$ \\
\hline
\end{tabular}

Note. ${ }^{* *}$ Correlation is significant at the 0.01 level (2-tailed).

* Correlation is significant at the 0.05 level (2-tailed).

\subsection{Education Equity and Individual Differences.}

Our third research question asked: What is the relationship among principals' focus on the attributes of education equity and variations in their personal, professional, and school variables? To answer this research question, we compared the composite scores of the participant by their individual differences. Our analysis revealed numerous differences and several conditions of non-significant relationships.

We found that the age of the principals was inversely correlated with the focus on student success and achievement $(r=-.24, p=.019)$. We found female principals $(N=64, M=4.00, S D=.64)$ had significantly higher levels $(t(125)$ $=2.28, p=.024)$ of advocating for education equity than males $(\mathrm{N}=63, M=3.75, S D=.60)$. We found African Americans principals $(\mathrm{N}=10, \mathrm{M}=2.60, \mathrm{SD}=1.17)$ agreed to a greater degree a need to devote more time to instructional leadership $(t(125)=2.56, p=.012)$ than Caucasian principals $(N=116, M=1.93, S D=.75)$, although both were within the disagree range of the scale.

Through our analysis we found multiple relationships based on school or community. We found a difference for advocating for educational equity by community type of the principals $[F(2,125)=5.63, p<.01]$ with the pairwise comparison (Tukey post-hoc) revealing principals in rural communities were significantly lower than principals in suburban and urban communities. We also found a relationship between the principals' community type and need 
to devote more time toward instructional leadership $[F(2,125)=3.41, p=.036]$ with the pairwise comparison (Tukey post-hoc) revealing urban principals feeling a greater need to devote more time than suburban principals.

Our analysis revealed a difference in engaging in activities that influence organizational culture and climate by school size $[F(5,122)=3.05, p=.013]$ with our pairwise comparison (Tukey post-hoc) revealing principals in schools with populations of 600 to 800 students engaging in higher levels influence activities than principals in schools with more than 1000 students.

We found principals in charter schools $(N=9, M=4.44, S D=.50)$ indicated that they advocated for educational equity at higher levels $(t(123)=2.94, p<.01)$ than principals in public schools $(N=116, M=3.82, \mathrm{SD}=.62)$. We also found principals in charter schools $(N=9, M=4.78, S D=.44)$ engaged in higher levels of focus on student success and achievement $(t(123)=2.36, p=.02)$ than principals in public schools $(N=116, M=4.31, S D=.58)$ however, both were in the agree to strongly agree range of the scale.

Our analysis did not reveal significant differences for the principals based on the social economic status of students in their schools, by the grade levels of their school, by the levels of students qualifying for free and reduced lunch in their schools, or by the government performance rankings (grade) of their schools.

\subsection{Principals Time Spent-Alignment with Equity Mindset}

Our fourth research question asked: Are the activities that principals spend the majority of their time on during a typical work week aligned with an education equity mindset? To answer this question, we examined the response of the principals to our item asking them to share the primary activity they dedicate the most time to during a typical work week. Our analysis revealed that $25 \%$ of the principals dedicate the majority of their time on student discipline and another $25 \%$ indicated the majority of their time was spent on classroom observations (see Figure 3 ). We did offer the participants an "other" option in our list of activities, to which $15 \%$ selected and indicated the time they spent was equally divided among multiple activities. There was about the same percent of participants who indicated the majority of their time was spent on email (14\%) and in administrative meetings (12\%). A smaller percentage indicated that the majority of their time was spent on personnel issues $(5 \%)$ and in reporting $(3 \%)$.

Using a Chi-squared analysis we were not able to detect any differences in the time dedication distributions by school type, school location, school system, school student population size, economic status of the students in the school, school performance ranking, nor of the percent of new teachers in the school annually. We also found no relation between the categories of principal time dedication and their age, years of experiences, or composite scores on the attributes of an education equity mindset. Interpreting our results, there seems to be no apparent trend to explain principals' dedication of the majority of their time during a typical work week based on our collected data. Thus, our data failed to reveal any relationships between principal time dedication and their education equity mindset attribute consideration or action.

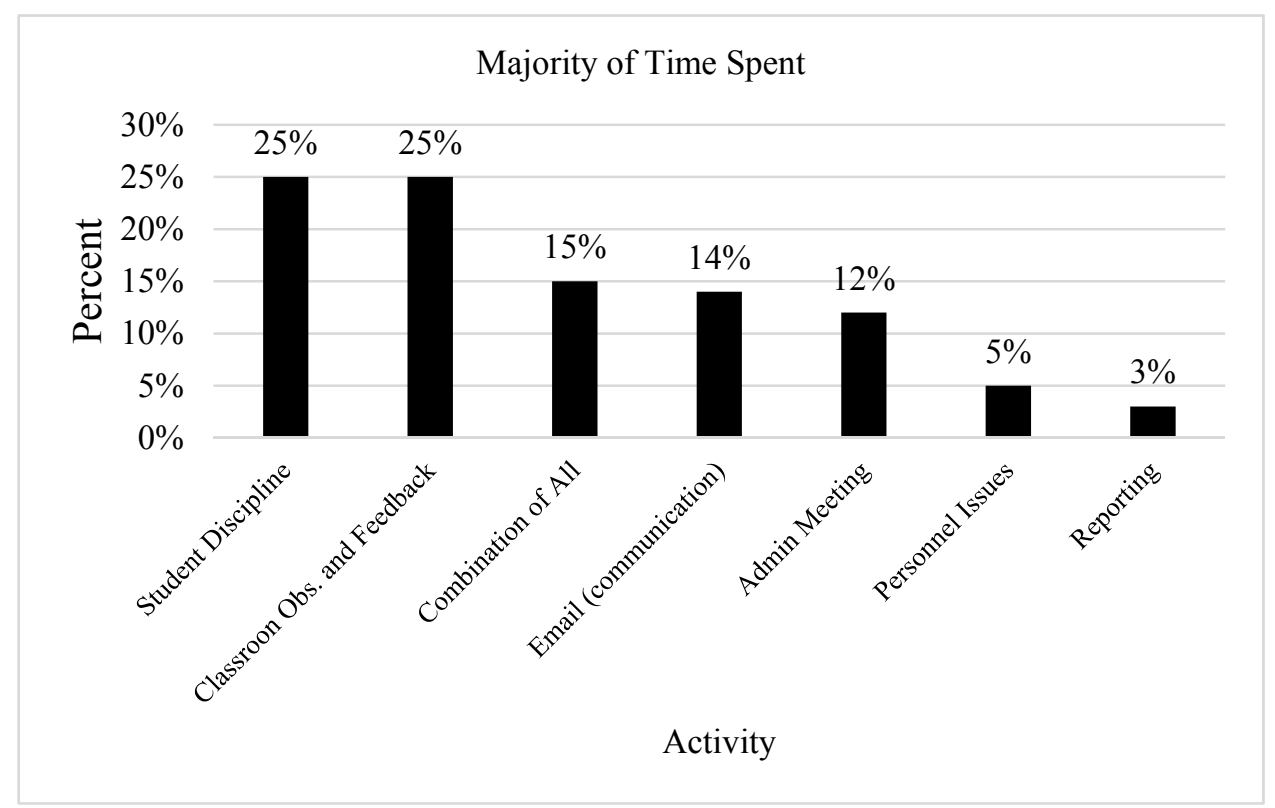

Figure 3. Percentage distribution to where the participants spend most of their time during a typical work week 


\section{Discussion and Implications}

The goal of our exploratory study was to determine, identify, and assess the attributes of an educational equity mindset among K-12 school principals to create a model of the mindset. We maintain an education equity mindset is fundamental to assuring all students are provided the opportunity to achieve to their highest capacity. In holding an educational equity mindset, principals are more likely to advocate for quality education for all students, create a climate and culture essential for equity in education, and promote success and achievement for all students. The mixed results of our research provide a foundation for ongoing research and exploration of principals' education equity mindset.

\subsection{Shared Attributes of an Education Equity Mindset}

We found a disconnect between the education equity mindset attributes principals communicated in their responses to the reasons that they became principals and the attributes they communicated in their descriptions of what they do to support student well-being. The principals' focused primarily on influence and reach in their explanations of why they became principals, while they focused primarily on culture and climate in their communication regarding student well-being. Our findings indicate that principals may compartmentalize their mindset depending on the conditions or situation they are considering. We speculate the compartmentalization of mindset attributes may result in fragmented expression of education equity mindset attributes which may limit the capacity of principals to effectively use their positions to support the achievement to highest capacity of all students. It may also be possible that the principals express actions associated with an education equity mindset, but may not hold the mindset in a way that guides all aspects of their practice, reflecting the potential of a social desirability bias. There is a need for additional research on when and why principals express attributes of an education equity mindset.

\subsection{Relation Among Attributes}

Through our analysis we found variations in the average levels of engagement and commitment to the education equity mindset and there were fewer correlated attributes than non-correlated attributes. We argue that the lack of correlation among the items reflects the different attributes of an education equity mindset, and while we maintain all the attributes are components of the mindset, they may be considered in different contexts making the consideration of the attributes individually highly contextual. For example, if a principal is working in a school with a high percentage of students living in poverty, the principal may be working on basic needs and, therefore, more focused on advocating for equity by creating opportunity for students to receive fundamental services and support. It is also likely combinations of individual, school, and community variables that influence the consideration of the attributes leading to complex variations in responses and the subsequent collective consideration of the relationships among the attributes. The focus on meeting basic needs may eclipse some of the mindset attributes such as instructional leadership. The implications for fragmented expression of the mindset attributes is the potential for some attributes to fall out of consideration resulting in a lack of a developed education equity mindset. There is a need to continue to explore school principal consideration and engagement in our education equity mindset attributes.

\subsection{Education Equity and Individual Differences}

We found a number of differences among our participants' consideration of and engaging in actions aligned with our attributes. More specifically we found differences in the levels of our attribute composite score based on gender, ethnicity, school location, school size, school grade level, and type of school system. We speculate that personal and professional experiences and the environment in which principals have differential influence on principal development of an education equity mindset. The implications for differences in the mindset based on personal, professional, and schools and settings, is likely a range of professional development needs to foster the principals' education equity mindset and internalization of the attributes. Further, if principals change school environments they may not be psychologically prepared to support the success for all students. An important next step in our research is the determination of the professional development needs of principals to catalyze their continued growth of an education equity mindset.

\subsection{How Principals Spend Time}

We found that half of the principals spent the majority of their time in a typical week engaged in student discipline or classroom observations. The combination of all our listed activities and communication was selected by about a third of the participants. We were perplexed by the responses given the qualitative responses and the average levels of the composite scores for our mindset attributes. We found essentially no communication of spending significant time on discipline in the qualitative data and was not reflected in the selected response items. We did find that the 
principals tended to indicate that they allocated adequate time toward instructional leadership which is more consistent with the time they allocated toward classroom observation and feedback. We speculate that principals are likely to perceive discipline as something they have to do, but do not consider the activity as part of why they became a principal or an activity they seek to engage in to support student well-being. The lack of relationship between the time spent responses and the individual variables or attribute composite scores suggests a lack of alignment between how principals spend their time and their perceived education equity mindset. How principals perceive their engagement in professional activities aligns with efforts to promote education equity is a needed direction of research.

\section{Limitations and Directions for Future Research}

This first limitation of our research is the participants were all recruited from the same region in the southern United States. While our sample was essentially representive of the distribution of principals in the region, it is highly likely principals in other regions or conditions may have different perspectives and experiences that would lead to the development and expression of different levels of our education equity mindset attributes. Examining the education equity mindset attributes of principals in other regions or working in other conditions is an excellent direction for future research.

The second limitation of our research is the under-representation of principals in under-performing schools. While the representation of the principals in under-performing schools in our sample was close to the regional percentage, there is a need to gather additional data from this group of principals. We speculate that the issues of education equity in under-performing schools are more pronounced and require creative solutions from principals. Exploring how principals in under-performing schools think about and engage in the attributes of an education equity mindset is a needed area of research.

A third limitation of our research is the nature of our data collection. While we gathered a combination of qualitative and quantitative data, we were not able to follow-up with the principals to determine why they responded the way they did. We do maintain our research is exploratory, so our study provides a foundation for future research. As we continue with our research, we intend to interview principals to delve deeper into their consideration and engagement in the attributes of an education equity mindset.

A fourth limitation is the exploratory nature of our research. While we have attempted to start creating a model representative of a principal education equity mindset based on the literature, we may have an inaccurate model. While we vetted our model attributes with experts in school leadership preparation, the principals may form a different set of attributes to guide their practice. Further, it may be possible the items in our survey, which we validated, may not be interpreted by the principals in ways aligned with an education equity mindset. Regardless, our work has laid a foundation for the ongoing research needed to define and document an education equity mindset of principals.

\section{Conclusion}

The goal of our exploratory study was to gather preliminary evidence to determine if principals hold an education equity mindset composed of six essential attributes and to validate our proposed model. We maintain that the examination and development of an education equity mindset among principals is critical for their support of the educational and societal challenges influencing student success. Our results indicate that the principals are likely to hold the mindset, but may be required to engage in other activities that limit their expression or actions aligned with some of the mindset attributes. Our results also reflect the likely situation of principals expressing elements of the mindset differently as the context for their work shifts. Our study left us with multiple questions and directions for future research to further explore the education equity mindset of principals.

\section{References}

Armor, D. A., \& Taylor, S. E. (2003). The effects of mindset on behavior: Self-regulation in deliberative and implemental frames of mind. Personality and Social Psychology Bulletin, 29(1), 86-95. https://doi.org/10.1177/0146167202238374

Barth, R. S. (2001). Learning by heart. San Francisco, CA: Jossey-Bass.

Brown, K. M. (2004). Leadership for social justice and equity: Weaving a transformative framework and pedagogy. Educational Administration Quarterly, 40(1), 77-108. https://doi.org/10.1177/0013161X03259147

Conley, D. T. (2011). Building on the common core. Educational Leadership, 68(6), 16-20.

Cubberley, E. (1916). Public school administration. Boston: Houghton Mifflin. 
Deal, T. E., \& Peterson, K. D. (2009). Shaping school culture: Pitfalls, paradoxes, and promises. San Francisco, CA: Jossy-Bass.

DeWitt, P. M. (2016). Collaborative leadership: Six influences that matter most. Thousand Oaks, CA: Corwin Press.

Dweck, C. (2007). Mindest: The new psychology of success. New York: Ballantine Books.

Ehren, B. J. (2009). Response to intervention in secondary school: Is it on your radar screen. Washington, D.C.: RtI Action Network.

Farrington, C. A., Roderick, M., Allensworth, E., Nagaoka, J., Keyes, T. S., Johnson, D. W., \& Beechum, N. O. (2012). Teaching adolescents to become learners: The role of noncognitive factors in shaping school performance: A critical literature review. Chicago: University of Chicago Consortium on Chicago School Research.

Finnigan, K., Daly, A., \& Che, J. (2012). The acquisition and use of evidence district-wide. Paper Presented as the Annual Meeting of the American Educational Research Association, Vancouver, Canada. Retrieved from http://www.wtgrantfoundation. org/resources/studying-the-use-of-research-evidence

French II, R. P. (2016). The fuzziness of mindsets: Divergent conceptualizations and characterizations of mindset theory and praxis. International Journal of Organizational Analysis, 24(4), 673-691. https://doi.org/10.1108/IJOA-09-2014-0797

Gardiner, M. E., \& Enomoto, E. K. (2006). Urban school principals and their role as multicultural leaders. Urban Education, 41(6), 560-584. https://doi.org/10.1177/0042085906294504

Gollwitzer, P. M., \& Bayer, U. (1999). Deliberative versus implemental mindsets in the control of action. In S. Chaiken \& Y. Trope (Eds.), Dual-process theories in social psychology (pp. 403-422). New York: Guilford Press.

Grigsby, B., Schumacher, G., Decman, J., \& Simieou III, F. (2010). A principal's dilemma: Instructional leader or manager. The Online Journal, 8(3), 3.

Gruenert. S. (2008). School culture, school climate: They are not the same thing (pp. 56-59). NAESP Principal. Retrieved from https://www.naesp.org/sites/default/file/resources/2/Principal/2008/M-Ap56.pdf

Haecker, B., Lane, F., \& Zientek, L. (2017). Evidence-based decision-making: Influences on central office administrators' decision-making practices. Journal of School Leadership, 27, 860-883. https://doi.org/10.1177/105268461702700604

Hallinger, P., \& Heck, R. H. (2010a). Collaborative leadership and school improvement: Understanding the impact on school capacity and student learning. School Leadership and Management, 30(2), 95-110. https://doi.org/10.1080/13632431003663214

Hallinger, P., \& Heck, R. H. (2010b). Leadership for learning: does collaborative leadership make a difference in school improvement? Educational Management Administration \& Leadership, 38(6), 654-678. https://doi.org/10.1177/1741143210379060

Hammond, Z. (2015). Culturally responsive teaching \& the brain: Promoting authentic engagement and rigor among culturally and linguistically diverse students. Thousand Oaks, CA: Corwin.

Hernandez, F., \& Kose, B. W. (2012). The developmental model of intercultural sensitivity: A tool for understanding principals' cultural competence. Education and Urban Society, 44(4), 512-530. https://doi.org/10.1177/0013124510393336

Hoy, W., Tarter, C., \& Kottkamp, P. (1991). Open schools/healthy schools. Newbury Park, CA: Sage Publications.

Hoyle, J., English, F., \& Steffy, B. (1985). Skills for successful leaders. Arlington, VA: American Association of School Administrators.

Hung, M., Smith, W. A., Voss, M. W., Franklin, J. D., Gu, Y., \& Bounsanga, J. (2019). Exploring student achievement gaps in school districts across the United States. Education and Urban Society, Online first. https://doi.org/10.1177/0013124519833442

Jordan, W. J. (2010). Defining equity: Multiple perspectives to analyzing the performance of diverse learners. Review of Research in Education, 34(1), 142-178. https://doi.org/10.3102/0091732X09352898

Kohn, A. (2008). Education progressive. Independent School, 67(3), 18-30. 
Leithwood, K., Harris, A., \& Hopkins, D. (2008). Seven strong claims about successful school leadership. School Leadership and Management, 28(1), 27-42. https://doi.org/10.1080/13632430701800060

Louis, K. S., Leithwood, K., Wahlstrom, K., \& Anderson, S. (2010). Learning from leadership: Investigating the links to improved student learning. New York: Final report of Research, The Wallace Foundation.

McKenzie, K., Christman, D., Hernandez, F., Fierro, E., Capper, C., Dantley, M., \& Scheurich, J. J. (2008). From the field: A proposal for educating leaders for social justice. Educational Administration Quarterly, 44, 111-138. https://doi.org/10.1177/0013161X07309470

Means, B., Padilla, C., DeBarger, A., \& Bakia, M. (2009). Implementing data-informed decision making in schools: Teacher access, supports, and use (Report No. ED-01-CO-0040). Washington, DC: U.S. Department of Education.

Mezirow, J. (2003). Transformative learning as discourse. Journal of Transformative Education, 1(1), 58-63. https://doi.org/10.1177/1541344603252172

Normore, A. (Ed.). (2008). Leadership for social justice. Charlotte, NC: Information Age.

Oakes, J. (2005). Keeping track: How schools structure inequality. New Haven, CT: Yale University Press.

Reddy, L., Ketter, R., \& Kurz, A. (2015). School-wide educator evaluation for improving school capacity and student achievement in high-poverty schools: Year 1 of the school system improvement project. Journal of Educational and Psychological Consultation, 25, 90-108. https://doi.org/10.1080/10474412.2014.929961

Riester, A. F., Pursch, V., \& Skrla, L. (2002). Principals for social justice: Leaders of school success for children from low-income homes. Journal of School Leadership, 12(3), 281-304. https://doi.org/10.1177/105268460201200303

Robinson, V. (2010). From instructional leadership to leadership capabilities: Empirical findings and methodological challenges. Leadership and Policy in Schools, 9(1), 1-26. https://doi.org/10.1080/15700760903026748

Rowley, S. R. (1991). A new mindset for restructuring schools. NASSP Bulletin, 75(537), $28-32$. https://doi.org/10.1177/019263659107553706

Santamaria, L. J., \& Santamaria, A. P. (2012). Applied critical leadership in education: Choosing change. New York, NY: Routledge. https://doi.org/10.4324/9780203818688

Scheurich, J. J., \& Skrla, L. (2003). Continuing the conversation on equity and accountability. In L. Skrla \& J. J. Scheurich (Eds.), Educational equity and accountability: Policies, paradigms, and politics (pp. 39-49). New York, NY: Routledge. https://doi.org/10.4324/9780203465615_chapter_4

Scigliano, D., \& Hipsky, S. (2010). 3 Ring circus of differentiated instruction. Kappa Delta Pi Record, 46(2), 82-86. https://doi.org/10.1080/00228958.2010.10516699

Shapiro, J. P. (2008). Ethics and social justice in the new DEEL: Addressing the paradox of control/democracy. In A. H. Normore (Ed.), Leadership for social justice: Promoting equity and excellence through inquiry and reflective practice (pp. 287-301). Charlotte, NC: Information Age.

Stanovich, P. J., \& Stanovich, K. E. (2003). Using research and reason in education: How teachers can use scientifically based research to make curricular \& instructional decisions. Washington, DC: The Partnership for Reading. https://doi.org/10.1037/e563842009-001

Taylor, S. E., \& Gollwitzer, P. M. (1995). Effects of mindset on positive illusions. Journal of Personality and Social Psychology, 69(2), 213. https://doi.org/10.1037/0022-3514.69.2.213

Theoharis, G. (2005). Arrogant humility: The identity, calling, and leadership of urban social justice principals. Paper presented at the University Council for Educational Administration Annual Convention, Nashville, TN.

Theoharis, G. (2008). "At every turn": The resistance that principals face in their pursuit of equity and justice. Journal of School Leadership, 18(3), 303-343. https://doi.org/10.1177/105268460801800304

Theoharis, G., \& Haddix, M. (2011). Undermining racism and a whiteness ideology: White principals living a commitment to equitable and excellent schools. Urban Education, 46(6), 1332-1351. https://doi.org/10.1177/0042085911416012

Tooms, A. K., \& Boske, C. (Eds.). (2010). Bridge leadership: Connecting educational leadership and social justice to improve schools. Charlotte, NC: Information Age. 
Turan, S., \& Bektas, F. (2013). The relationship between school culture and leadership practices. Egitim Arastirmalari-Eurasian Journal of Educational Research, 52, 155-168.

U.S. Department of Education. (2015). Every student succeeds act (ESSA). Washington, DC: Author. Retrieved from http://www.ed/gov/essa.

U.S. Department of Education, U.S. National Commission on Excellence in Education. (1983). A nation at risk: The imperative for educational reform. Washington, DC: Author.

Weiss, I. R., \& Pasley, J. D. (2004, February). What is high-quality instruction? Educational Leadership, 61(5), 24-28.

Williams, J., Friesen, S., Milton, P., \& Canadian Education, A. (2009). What did you do in school today? Transforming classrooms through social, academic, and intellectual engagement. Online Submission, Retrieved from ERIC database.

Yair, G. (2000). Educational battlefields in America: The tug of war over students' engagement with instruction. Sociology of Education, 73(4), 247-269. https://doi.org/10.2307/2673233

\section{Note}

All co-authors listed alphabetically and contributed equally to the work

\section{Copyrights}

Copyright for this article is retained by the author, with first publication rights granted to the journal.

This is an open-access article distributed under the terms and conditions of the Creative Commons Attribution license (http://creativecommons.org/licenses/by/4.0/). 